\title{
Inhibition of Notch1 signaling overcomes resistance to the death ligand Trail by specificity protein 1-dependent upregulation of death receptor 5
}

\author{
A Fass ${ }^{1,3}{ }^{13}$ KE Tagscherer ${ }^{1}$, J Richter ${ }^{1}$, J De-Castro Arce ${ }^{2}$, C Savini ${ }^{2}$, F Rösl ${ }^{2}$ and W Roth ${ }^{\star, 1}$
}

The Notch1 signaling pathway contributes to tumorigenesis by influencing differentiation, proliferation and apoptosis. Here, we demonstrate that inhibition of the Notch1 signaling pathway sensitizes glioblastoma cell lines and glioblastoma initiating cells to apoptosis induced by the death ligand TRAIL. This sensitization occurs through transcriptional upregulation of the death receptor 5 (DR5, TRAIL-R2). The increase in DR5 expression is abrogated by concomitant repression of the transcription factor Sp1, which directly binds to the $D R 5$ promoter in the absence of Notch1 as revealed by chromatin immunoprecipitation. Consistent with these findings, Notch1 inhibition resulted in increased DR5 promoter activity, which was impaired by mutation of one out of two Sp1binding sites within the proximal DR5 promoter. Moreover, we demonstrate that JNK signaling contributes to the regulation of DR5 expression by Notch1. Taken together, our results identify Notch1 as key driver for TRAlL resistance and suggest Notch1 as a promising target for anti-glioblastoma therapy.

Cell Death and Disease (2015) 6, e1921; doi:10.1038/cddis.2015.261; published online 15 October 2015

Notch signaling plays a major role in tumorigenesis by influencing differentiation, proliferation and apoptosis. The components of the pathway comprise four Notch receptors (Notch1-4) and their corresponding membrane bound ligands Delta-like (DII1, DII3 and DII4) and Jagged (Jag1 and Jag2). Ligand binding induces a conformational change in the receptor enabling cleavage by the metalloproteinase ADAM (a disintegrin and metalloprotease). This in turn causes exposure of a second cleavage site and subsequent proteolysis by the $\gamma$-secretase complex which results in the release of Notch intracellular domain (NICD). NICD translocates to the nucleus and forms a transcriptional complex with C-promoter binding factor 1 (CBF1), Mastermind (MAML) and transcriptional co-activators thereby converting CBF1 from a transcriptional repressor into an activator. ${ }^{1,2}$ The most prominent NICD target genes belong to the hairy and enhancer of split-1 (HES) ${ }^{3}$ - and Hey-family ${ }^{4}$ of transcriptional repressors. Additionally, several other targets including CyclinD1, ${ }^{5}$ c-myc, ${ }^{6}$ p21, ${ }^{7}$ and survivin $^{8}$ were identified, indicating that Notch signaling is involved in tumorigenesis and cell death resistance.

The death ligand tumor necrosis factor-related apoptosis inducing ligand (TRAIL) is a member of the tumor necrosis factor superfamily, which initiates extrinsic cell death via binding to the death receptors DR4 (TRAIL-R1) and DR5 (TRAIL-R2). Upon ligand binding, the death inducing signaling complex (DISC) assembles resulting in the cleavage of pro-Caspase 8 and the initiation of apoptosis. ${ }^{9}$ TRAIL has been shown to selectively kill malignant rather than normal cells with the underlying reasons still being elusive. ${ }^{10}$ Initial clinical trials revealed that treatment with both human recombinant TRAIL and TRAIL-agonistic human antibodies is generally well tolerated and non-toxic. ${ }^{11}$ However, TRAIL resistance of tumor cells has frequently been observed ${ }^{12}$ resulting in an increased interest in the restoration of TRAIL sensitivity by combination therapies.

We previously reported that Notch1 signaling promotes survival of glioblastoma cells via epidermal growth factor receptor (EGFR)-mediated induction of anti-apoptotic Mcl-1. ${ }^{13}$ This EGFR-dependent regulation of the anti-apoptotic Mcl-1 protein results in a decreased susceptibility to activators of both the extrinsic and intrinsic apoptotic pathway which can be overcome by Notch1 inhibition. Within this study, we specifically concentrated on mechanisms of Notch1dependent regulation of death receptor-mediated apoptosis. We demonstrate that inhibition of Notch1 sensitizes glioblastoma

\footnotetext{
${ }^{1}$ Molecular Tumor Pathology, German Cancer Research Center, Im Neuenheimer Feld 280, 69120 Heidelberg, Germany, and Institute of Pathology, Im Neuenheimer Feld 224, 69120 Heidelberg, Germany and 2Division of Viral Transformation Mechanisms, German Cancer Research Center, Im Neuenheimer Feld 280, 69120 Heidelberg, Germany

*Corresponding author: W Roth, Molecular Tumor Pathology, German Cancer Research Center, Im Neuenheimer Feld 280, Institute of Pathology, 69120 Heidelberg, Germany. Tel: +49 622156 4174; Fax: +49 6221 42 3630; E-mail: Wilfried.Roth@med.uni-heidelberg.de

${ }^{3}$ Present address: Department of Cancer Biology, Dana-Farber Cancer Institute, and Department of Genetics, Harvard Medical School, Boston, MA 02215, USA.

Abbreviations: ADAM, a disintegrin and metalloprotease; AP1, activator protein 1; ATCC, American type culture collection; BNIP3, BCL2 and adenovirus E1B 19 kDainteracting protein 3; CBF1, C-promoter binding factor; ChIP, Chromatin immunoprecipitation; CHOP, CCAAT-enhancer-binding protein homologous protein; DISC, death inducing signaling complex; DLL, Delta-like; DR4, death receptor 4; DR5, death receptor 5; EGFR, epidermal growth factor receptor; Egr-1, early-growth-response gene product 1; ERK1/2, extracellular-signal-regulated kinase 1/2; FLIP, FLICE-inhibitory protein; GSI, $\gamma$-secretase inhibitor; HES, hairy and enhancer of split 1; ITGB4, integrin B4; Jip1, JNK-interacting protein 1; JNK, Jun N-terminal Kinase; MAML, mastermind; MOI, multiplicity of infection; NF $k B$, nuclear factor $\kappa B$; NICD, Notch intracellular domain; SD, standard deviation; Sp1, specificity protein 1; Stat1, signal transducer and activator of transcription 1; STS, Staurosporine; TRAIL, tumor necrosis factor-related apoptosis inducing ligand; YY1, Ying-Yang 1

Received 24.2.15; revised 04.8.15; accepted 05.8.15; Edited by T Kaufmann
} 
cells to TRAIL-induced cell death by transcriptional upregulation of DR5 expression. Notch1-dependent alteration in DR5 gene transcription is mediated by the specificity protein 1 (Sp1) transcription factor and involves Jun N-terminal kinase (JNK) signaling. This novel Notch1-Sp1-DR5 signaling pathway could be exploited in future therapeutic approaches for glioblastoma.

\section{Results}

Notch1 inhibition sensitizes glioblastoma cells for TRAIL-induced apoptosis. Our previous work suggested an important role of Notch1 in the regulation of apoptosis resistance in glioblastoma cells. ${ }^{13}$ Given the therapeutic potential of TRAIL as a natural anti-tumor agent we sought to elucidate the crosstalk between Notch1 and the extrinsic apoptotic pathway. As a first step, we confirmed the sensitization of glioblastoma cells to TRAIL-induced apoptosis following Notch1 inhibition using long-term cell lines, primary cultures, and glioblastoma initiating cells (Figure 1a). Notch1 knockdown was achieved by an adenovirus delivering a Notch1-specific shRNA. Furthermore, TRAIL treatment in combination with Notch1 downregulation strongly reduced colony formation (Figure 1b). Importantly, human (nontransformed) primary astrocytes were not sensitized to TRAIL by inhibition of the Notch1 pathway (Figure 1c).

Notch1 signaling regulates expression of the DR5 protein. Suppression of Notch1 signaling resulted in a substantial upregulation of the death receptor DR5 as assessed by immunoblot analysis (Figure 2a). Elevation of DR5 protein levels was accompanied by an increase in DR5 mRNA (Figure $2 b$ ). Importantly, the increase of DR5 protein after Notch1 knockdown was also detectable at the cell surface as determined by flow cytometry and membrane fractionation, respectively (Figure 2c). Consistently, overexpression of NICD resulted in decreased DR5 protein and mRNA levels (Figures 2d and e). To test whether DR5 upregulation can also be achieved by pharmacological inhibition of Notch activation, we treated cells with the ADAM17 inhibitor GW280264X. ADAM17, together with ADAM10, are the metalloproteinases mediating the initial cleavage of the Notch1 receptor following ligand binding. As expected, treatment with GW280264X resulted in an inhibition of Notch signaling as determined by expression levels of Hey1, a prominent Notch target gene. Importantly, this was paralleled by a substantial increase in DR5 mRNA levels (Figure 2f).

Besides DR5, the death receptor DR4 can also significantly contribute to apoptosis induced by TRAIL treatment in many tumor entities. Although DR4 has been shown to have a minor role in glioblastomas by several studies, ${ }^{14-16}$ we wanted to exclude any contribution of DR4 to the observed TRAIL sensitization upon Notch1 inhibition. Therefore we tested expression and cell surface density of DR4 in the cell lines used. Although DR4 is almost undetectable in S24 cells (Figure S1A right panel), U251MG and NCH468 cell express DR4 but it is not detectable at the cell surface (Supplementary Figure S1A left panel, S1B). Moreover, Notch1 inhibition has no effect on total protein levels of DR4 in U251MG and $\mathrm{NCH} 468$ cells. In line with this, knockdown of DR5 using a DR5-specific siRNA oligonucleotide completely abrogated the sensitization of cells to TRAIL-mediated apoptosis upon Notch1 inhibition (Figure $2 \mathrm{~g}$ ) confirming DR5 as the main signal transducing TRAIL receptor in glioblastomas.

To further confirm the relevance of DR5 upregulation after Notch1 knockdown for TRAIL-induced apoptosis in glioblastomas, we analyzed the extent of caspase-8 activation and DISC-formation following TRAIL-treatment. Using immunoblot analysis we observed both, a significantly increased caspase8 cleavage (Figure $3 a$ ) and DISC-formation (Figure 3b) upon TRAIL treatment with concomitant Notch1 inhibition.

Notch1 regulates DR5 via the transcription factor Sp1. To elucidate the mechanism underlying the increased expression of DR5 following Notch1 inhibition we examined the involvement of transcriptional regulators known to induce DR5 expression. Several previous studies have identified the transcription factor CCAAT-enhancer-binding protein homologous protein (CHOP) as a potent inductor of DR5 expression following various stimuli in glioma cells. ${ }^{17,18}$ However, we did not observe an increased CHOP expression upon Notch1 inhibition (data not shown).

Another activator of DR5 gene expression is the transcription factor Sp1. ${ }^{19,20}$ However, Sp1-mediated induction of DR5 expression has not yet been reported in gliomas. To examine a putative role of $\mathrm{Sp} 1$ in Notch1-dependent regulation of DR5, we downregulated Sp1 using Sp1-specific siRNA oligonucleotides. Remarkably, concomitant inhibition of Notch1 signaling failed to increase DR5 expression, both on the protein and mRNA level (Figures $4 a$ and b). Moreover, a significantly decreased density of DR5 was observed at the cell surface in cells transfected with Sp1 siRNA on top of Notch1 inhibition (Figure 4c). Of note, the expression level and subcellular localization of Sp1 remained unchanged following Notch1 knockdown (Figure 4d).

To further determine whether Notch1 signaling modulates binding of Sp1 to the DR5 promoter we performed chromatin immunoprecipitation experiments. Indeed, Sp1 significantly accumulated at the DR5 promoter upon Notch1 inhibition (Figure 4e) thereby accounting for the increased DR5 expression. Yoshida et al. ${ }^{21}$ described two putative Sp1binding sites within the proximal DR5 promoter and both sites have been included in the chromatin immunoprecipitation (ChIP) amplicon used for determination of Sp1-binding to the DR5 promoter within our study. To further analyze the functional relevance of these sites in the Notch1-mediated regulation of the DR5 promoter activity we performed reporter gene assays. Although the full-length promoter showed a strong increase in its activity upon Notch1 inhibition, mutation of the Sp1-binding site 1 (the one further away from the start site) completely abrogated DR5 promoter activation following Notch1 knockdown (Figure 4f). However, induction of the DR5 promoter remained unchanged when Sp1-binding site 2 (most proximal) was mutated (Figure 4f). Therefore, binding of Sp1 to the Sp1-binding site 1 is necessary and sufficient for Notch1-mediated regulation of DR5 promoter activity in glioma cells. 
a

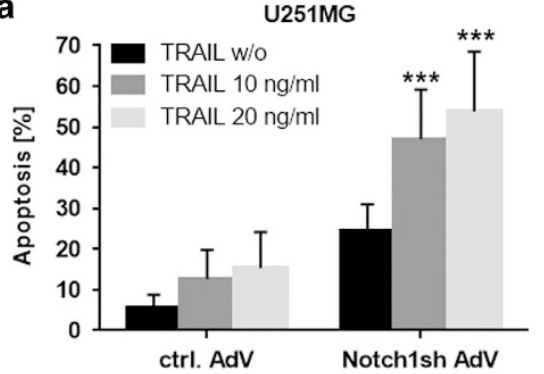

b

ctrl. AdV

TRAIL

w/o

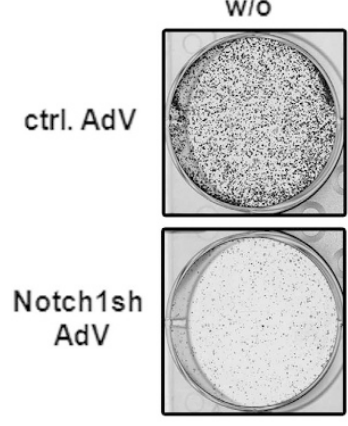

TRAIL

$20 \mathrm{ng} / \mathrm{ml}$
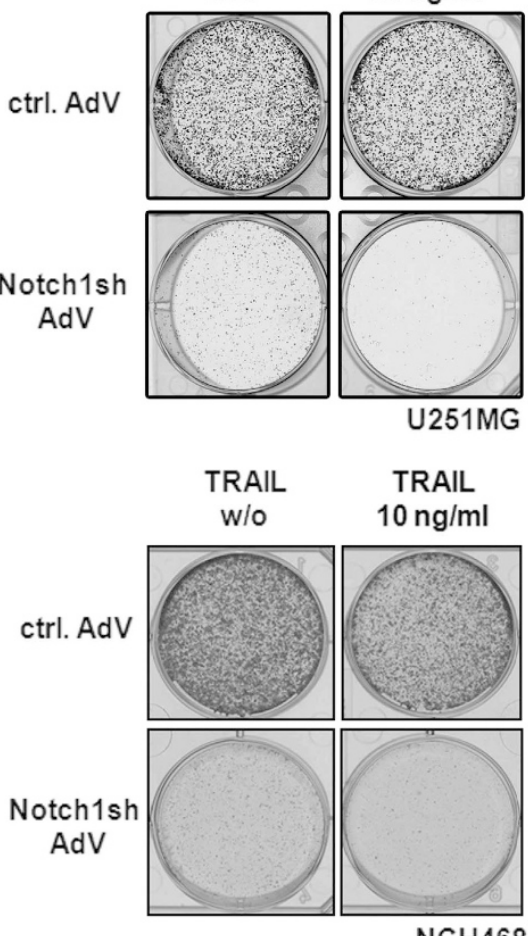

$\mathrm{NCH} 468$
$\mathrm{NCH} 468$

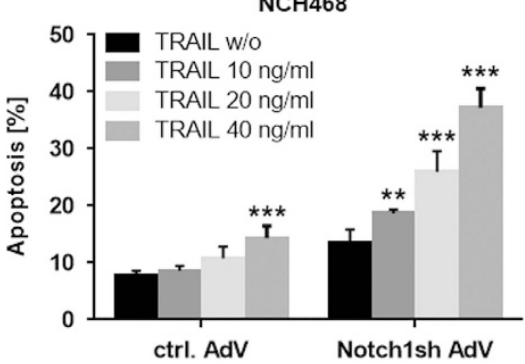

ctrl. AdV

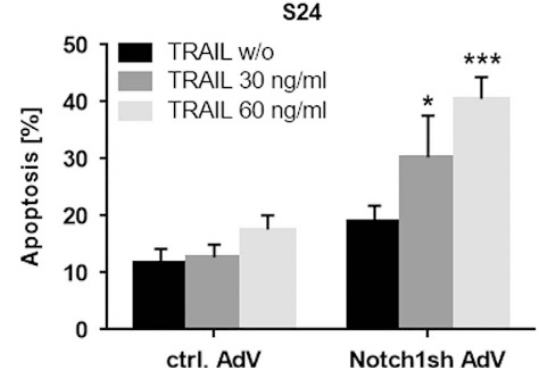

ctrl. AdV
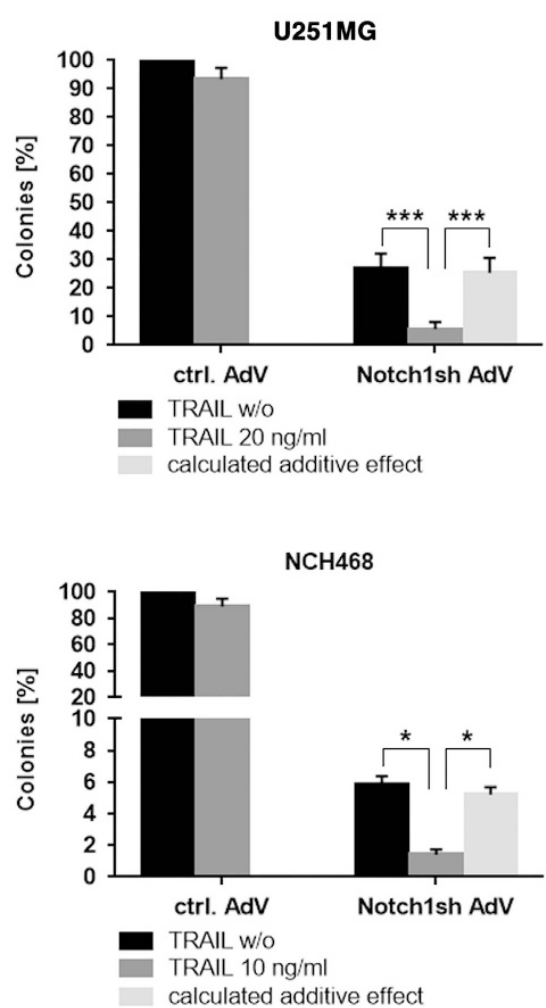

C

$\begin{array}{lccccccccc}\text { TRAIL [ng/ml] } & - & - & 20 & 40 & 60 & - & 20 & 40 & 60 \\ \text { STS [nM] } & 250 & - & - & - & - & - & - & - & - \\ \text { ctrl. AdV } & - & + & + & + & + & - & - & - & - \\ \text { Notch1sh AdV } & - & - & - & - & - & + & + & + & +\end{array}$

Notch1sh AdV - $\quad-\quad-\quad-c_{-}^{-}++++$

Notch1

Caspase-3

cleaved

Caspase-3

GAPDH
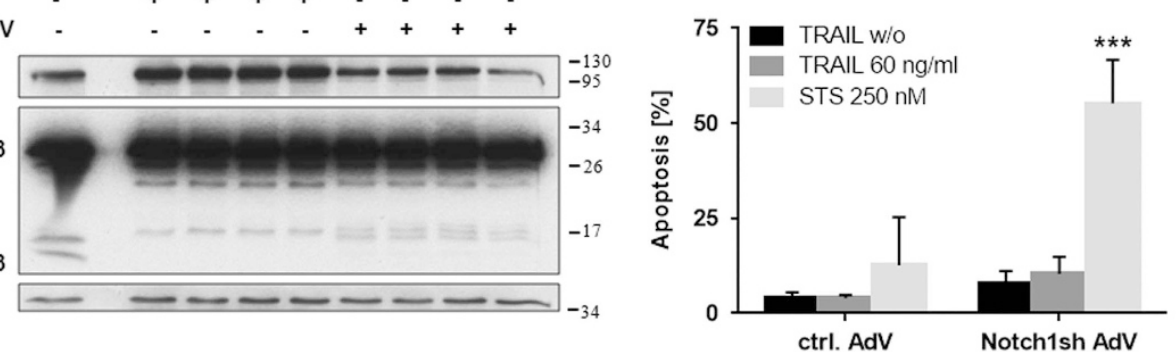

Figure 1 Notch1 inhibition sensitizes glioblastoma cells for TRAIL treatment. (a) Glioblastoma cells (U251MG-long-term cell line; NCH468-primary culture; S24-glioblastoma initiating cells) transduced with control-AdV or Notch1sh-AdV $(72 \mathrm{~h}$ ) were treated with TRAIL for $24 \mathrm{~h}$ (increased TRAlL concentrations were used for S24 cells because of the high TRAIL resistance of cancer-initiating cells). Apoptotic cell death was measured by flow cytometry $(n=3$; mean \pm S.D.). P-values were determined by two-way ANOVA. (b) Notch1 inhibition together with TRAIL treatment strongly reduces colony formation of glioblastoma cells. Control-AdV and Notch1sh-AdV transduced U251MG and NCH468 cells were seeded in 6-well plates $24 \mathrm{~h}$ post transduction (U251MG: $1 \times 10^{4}$ cells; NCH468: $4 \times 10^{4}$ cells). Cells were treated with TRAlL $48 \mathrm{~h}$ following seeding and $72 \mathrm{~h}$ post transduction, respectively. Colony growth was assessed by crystal violet staining 6 days (U251MG) or 5 days (NCH468) after seeding. Representative staining results are shown (left panels). Colony growth was quantified from three independent assays (right panels). P-values were determined by one-way ANOVA test. (c) Notch1 inhibition followed by TRAIL treatment does not target astrocytes. Human astrocytes transduced with control-AdV or Notch1sh-AdV (72 h) were treated with varying concentrations of TRAIL or $250 \mathrm{nM}$ STS for $24 \mathrm{~h}$. Total cell lysates were subjected to immunoblot analysis for Notch1 and Caspase-3 (left panel) or apoptotic cell death was measured by flow cytometry $(n=3$; mean \pm S.D.) (right panel). $P$-values were determined by two-way ANOVA. STS treated astrocytes served as a positive control for Caspase-3 cleavage and apoptosis, respectively 
JNK is involved in Notch1-mediated DR5 regulation. Increased transcriptional activity of Sp1 towards the DR5 promoter has formerly been associated with JNK. ${ }^{19}$ Interest- ingly, we observed that Notch1 inhibition is accompanied by JNK activation in glioma cells (Figure 5a). To examine whether JNK is involved in the upregulation of DR5 following

a
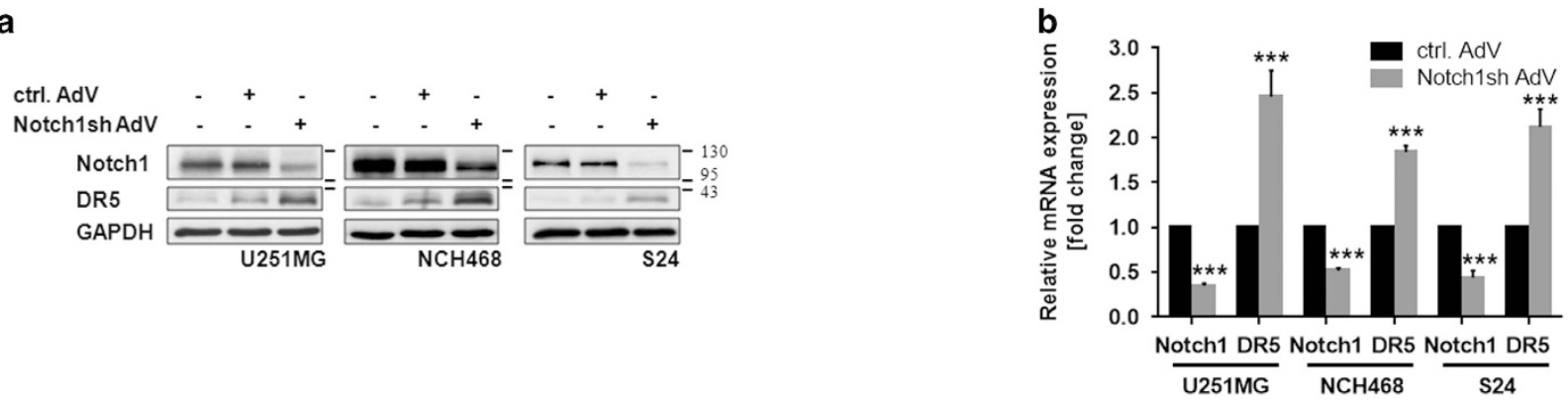

c
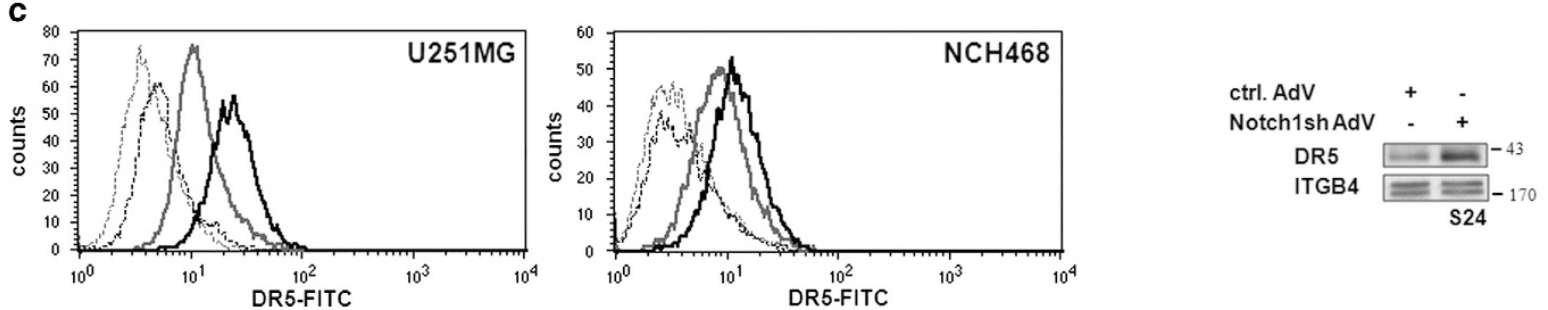

$=--\lg$ G control; ctrl. AdV
- DR5; ctrl. AdV

--- IgG control; Notch1sh AdV

d

DR5; Notch1sh AdV

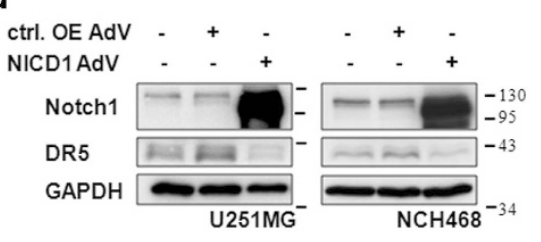

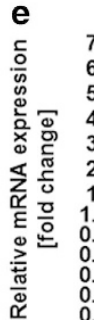
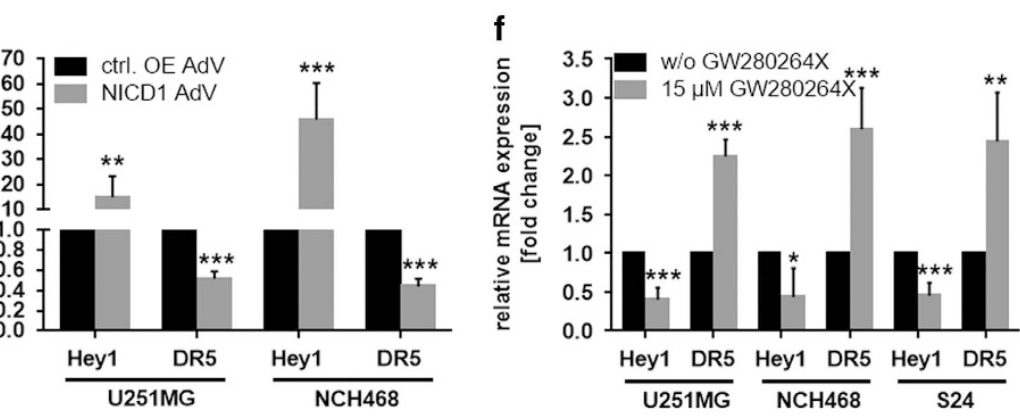

g
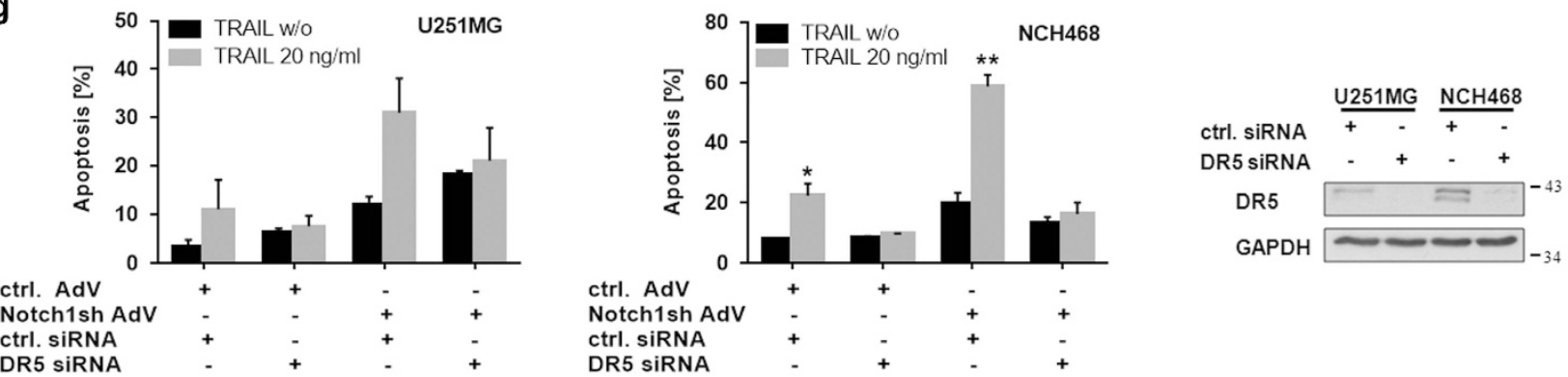

Figure 2 Notch1 signaling regulates the DR5 protein. (a) Immunoblot analysis of Notch1 and DR5 in wild type, control-AdV and Notch1sh-AdV transduced U251MG, NCH468 and S24 cells $72 \mathrm{~h}$ post transduction. (b) Quantitative real-time PCR analysis of Notch1 and DR5 mRNA expression in control-AdV and Notch1sh-AdV transduced glioblastoma cells $72 \mathrm{~h}$ post transduction. Expression data were normalized to internal $18 \mathrm{~S} r R N A$ expression $(n=3$, mean \pm S.D.). $P$-values were determined by $t$-test. (c) Inhibition of Notch1 signaling increases the amount of DR5 at the cell surface. Amount of DR5 located at the membrane was determined by flow cytometry using a FITC-labeled anti-DR5 antibody and a FITClabeled IgG as a control (left and middle panel) or by performing membrane fractionation (right panel). For the latter ITGB4 served as a loading control. (d) Immunoblot analysis of Notch1 and DR5 in wild type, control OE-AdV (empty), and NICD1-AdV transduced glioblastoma cells $72 \mathrm{~h}$ post transduction. (e) Quantitative real-time PCR analysis of the Notch1 target gene Hey1 and DR5 mRNA expression in control OE-AdV (empty) and NICD1-AdV transduced glioblastoma cells $72 \mathrm{~h}$ post transduction. Expression data were normalized to internal $18 \mathrm{~S}$ rRNA expression ( $n=3$, mean \pm S.D.). $P$-values were determined by $t$-test. (f) Quantitative real-time PCR analysis of the Notch1 target gene Hey1 and DR5 mRNA expression in U251MG, NCH468 and S24 cells following treatment with the ADAM inhibitor GW280264X (15 $\mu \mathrm{M})$ for $48 \mathrm{~h}$. Expression data were normalized to internal $18 \mathrm{~S}$ rRNA expression ( $n=3$, mean \pm S.D.). P-values were determined by t-test. (g) Control-AdV and Notch1sh-AdV transduced U251MG and NCH468 cells ( $24 \mathrm{~h}$ ) were transfected with control siRNA and DR5 siRNA, respectively. Cells were treated with TRAIL $48 \mathrm{~h}$ post transfection for $24 \mathrm{~h}$. Apoptotic cell death was measured by flow cytometry ( $n=2 ;$ mean \pm S.D.). $P$-values were determined by $t$-test (left and middle panel). Immunoblot analysis for DR5 $48 \mathrm{~h}$ post transfection (right panel) 


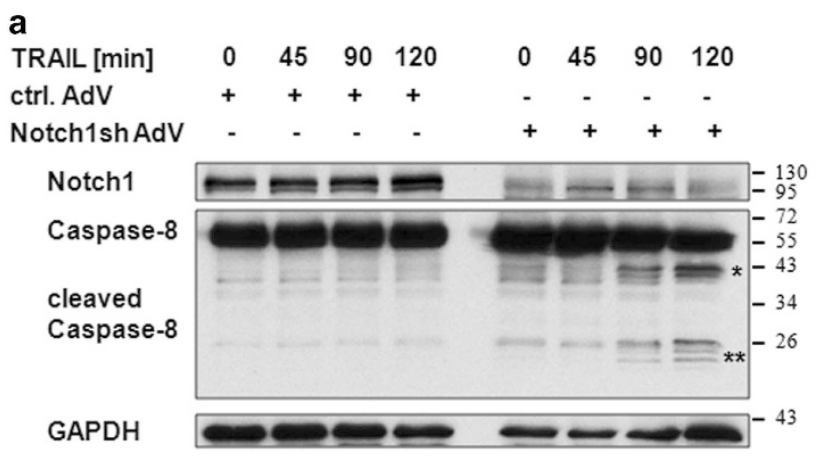

b
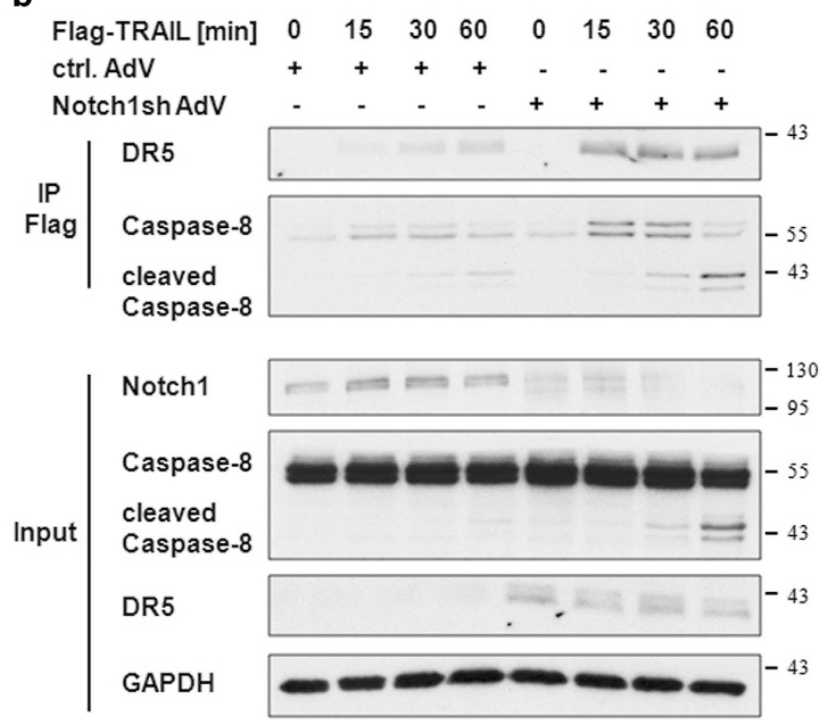

Figure 3 Inhibition of Notch1 signaling causes an increased Caspase-8 cleavage and DISC formation upon TRAIL treatment. (a) U251MG cells transduced with control-AdV or Notch1sh-AdV $(72 \mathrm{~h})$ were treated with TRAlL $(40 \mathrm{ng} / \mathrm{ml})$ for the indicated times. Total cell lysates were subjected to immunoblot analysis for Notch1 and Caspase-8. Asterisk indicate cleaved Caspase-8 fragments $\left({ }^{*}=p 41 / p 43 ;{ }^{* *}=\right.$ p24/p26). (b) Control-AdV and Notch1sh-AdV transduced U251MG cells (72 h) were treated with Flag-TRAlL $(500 \mathrm{ng} / \mathrm{ml})$ for the indicated time points. Subsequently, Flag was immunoprecipitated and immunoblots were probed with DR5 and Caspase-8 antibodies. Whole cell lysates were used for input controls

Notch1 knockdown, we blocked JNK activation using the JNK inhibitor SP600125. Concomitant Notch1 and JNK inhibition significantly decreased upregulation of DR5 (Figure 5b) pointing to an involvement of JNK in Notch1-dependent, Sp1-mediated regulation of DR5.

\section{Discussion}

Targeting of death receptors has been proposed as a novel anti-glioblastoma therapeutic approach since the discovery that TRAIL might selectively kill cancer cells. Despite promising preclinical in vitro and in vivo studies ${ }^{22-24}$ first clinical trials using TRAIL as a single agent have been disappointing since only modest overall anti-tumor activity was observed in patients with advanced malignancies. ${ }^{25}$ Nevertheless, both recombinant TRAIL and TRAIL receptor agonists have been proven to be non-toxic and well tolerated. ${ }^{11}$ The search for treatment options promoting TRAIL-mediated tumor cell killing is therefore as intense as ever. One major cause for the insufficient response to TRAIL treatment is a strong intrinsic and/or acquired resistance of tumor cells to TRAIL-induced apoptosis. In glioblastomas several resistance mechanisms are known including high expression of TRAIL-decoy receptors, ${ }^{26}$ epigenetic silencing of the TRAIL receptor DR4, ${ }^{15}$ overexpression of the antiapoptotic protein FLICE-inhibitory protein (FLIP), ${ }^{27}$ and altered expression of the Bcl-2 family members, which negatively interfere with TRAIL-induced apoptosis. ${ }^{28,29}$

We have previously shown that Notch1 is a central regulator of apoptosis susceptibility in glioblastoma cells. ${ }^{13}$ Here, we analyzed the molecular mechanisms of the strong sensitization of glioblastoma cells to TRAIL-induced apoptosis following inhibition of Notch1 signaling. We identified Notch1 as a mediator of transcriptional repression of DR5. In line with our results, inhibition of Notch1 signaling pathway in breast cancer cells has recently been reported to increase the expression of DR4 and DR5 and to enhance the sensitivity to TRAIL-induced apoptosis. ${ }^{30}$ In contrast to these findings, activation of Notch1 signaling increased DR5 expression levels in a p53-dependent manner in hepatocellular carcinoma, ${ }^{31}$ pointing to a cell type dependent regulation.

Transcriptional regulation of DR5 in glioblastoma has so far been linked to $\mathrm{CHOP}^{17}$ and BNIP3 (BCL2 and adenovirus E1B $19 \mathrm{kDa}$-interacting protein 3$)^{32}$ transcription factors, with the latter functioning as a transcriptional repressor. In other tumor entities, transcription of DR5 was shown to be activated by nuclear factor $\kappa \mathrm{B}(\mathrm{NF} \kappa \mathrm{B})$, signal transducer and activator of transcription 1 (Stat1), p53 and Sp1 and repressed by Ying-Yang 1 (YY1). ${ }^{33}$ Although a Sp1dependent regulation of DR5 was demonstrated in hepatocellular carcinoma, ${ }^{20,34}$ breast cancer, ${ }^{35}$ colorectal cancer, ${ }^{36}$ and ovary cancer, ${ }^{37}$ a Notch1-mediated regulation of Sp1 and, consequently, the existence of a functional Notch1/Sp1/DR5 axis was so far unknown.

We further evaluated the impact of JNK signaling in Notch1dependent DR5 regulation. In accordance with our study, modulation of JNK activity by Notch1 has recently been reported. ${ }^{30}$ It has further been proposed, that NICD1 directly binds to and thereby suppresses the scaffold activity of JNKinteracting protein 1 (Jip1) thus preventing the activation of JNK. $^{38}$ JNK was described to phosphorylate the Sp1 transcription factor at Thr278 which increases its stability and prevents its degradation. ${ }^{39,40}$ Further, JNK-dependent phosphorylation of Sp1 at Thr739 repressed sumoylation of Sp1, thereby blocking the binding of a SUMO-activated 
a

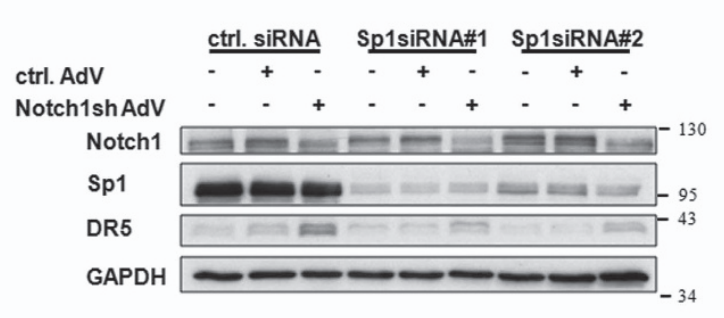

b

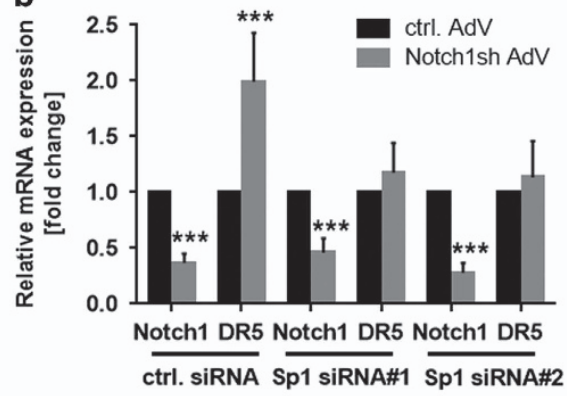

c
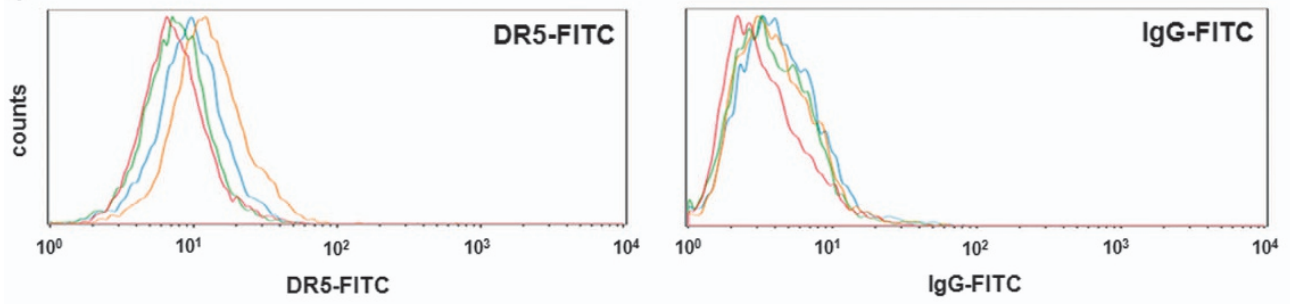

ctrl. AdV + ctrl. siRNA

$\square$ ctrl. AdV + Sp1 siRNA\#1

$\square$ Notch1sh AdV + ctrl. siRNA

- Notch1sh AdV + Sp1 siRNA\#1

d

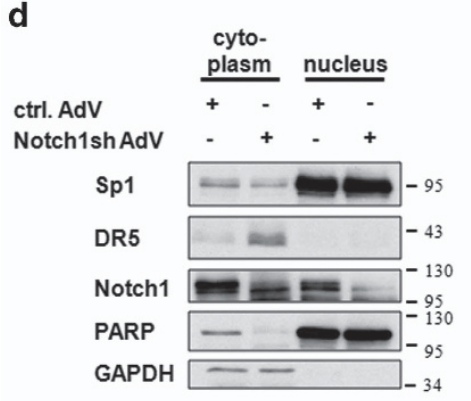

e

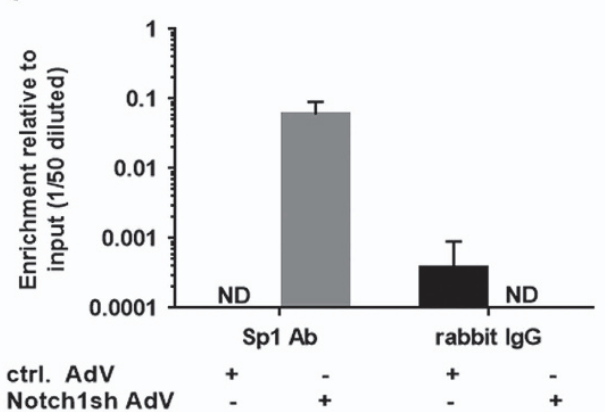

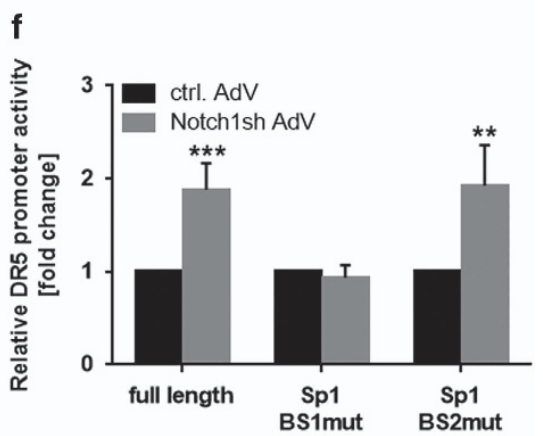

Figure 4 Notch1 regulates DR5 via the transcription factor Sp1. (a and b) U251MG cells transduced with control-AdV or Notch1sh-AdV were transfected with Sp1 siRNA oligonucleotides $24 \mathrm{~h}$ post transduction. (a) Immunoblot analysis for Notch1, Sp1, and DR5 $72 \mathrm{~h}$ post transduction. (b) Quantitative real-time PCR analysis of Notch1 and DR5 mRNA expression $72 \mathrm{~h}$ post transduction. Expression data were normalized to internal $18 \mathrm{~S}$ rRNA expression $(n=3$, mean \pm S.D.). P-values were determined by $t$-test. (c) U251MG cells transduced with control-AdV or Notch1sh-AdV were transfected with Sp1 siRNA oligonucleotides $24 \mathrm{~h}$ post transduction. Amount of DR5 located at the cell membrane was determined by flow cytometry $48 \mathrm{~h}$ post transfection using a FITC-labeled anti-DR5 antibody (left panel) and a FITC-labeled IgG as a control (right panel). (d) Cytoplasmic and nuclear levels of Sp1 remain stable following Notch1 knockdown. Immunoblot analysis for Notch1 and Sp1 in cytoplasmic and nuclear lysate fractions from wild type, control-AdV and Notch1sh-AdV-transduced U251MG cells $72 \mathrm{~h}$ post transduction. (e) Binding of Sp1 to the DR5 promoter is strongly enhanced following Notch1 downregulation. ChIP analysis of Sp1-binding to the DR5 promoter in U251MG cells transduced with control-AdV or Notch1sh-AdV (72 h) $(n=2 ;$ mean \pm S.D.). Rabbit lgG was used as a control for unspecific binding. (f) Relative DR5 promoter activity measured in U251MG cells transduced with control-AdV or Notch1sh-AdV using luciferase reporter constructs containing either the full-length DR5 promoter (-198 bp) or the DR5 promoter with mutated Sp1-binding site 1 (Sp1 BS1mut) and mutated Sp1-binding site 2 (Sp1 BS2mut), respectively $(n=3$; mean \pm S.D.). $P$-values were determined by $t$-test. ND, not detected

E3-ubiquitin ligase and increasing the stability of Sp1. ${ }^{41}$ However, we did not observe altered expression levels of Sp1 upon Notch1 downregulation. Nevertheless, JNK is capable of additionally regulating the activity of $\mathrm{Sp} 1$ in an indirect manner without affecting its expression levels. The JNK target c-jun directly binds to Sp1 resulting in an enhanced Sp1 activity. ${ }^{42,43}$ Further, $\mathrm{Sp} 1$ is similarly affected by binding to early growth-response gene product 1 (Egr-1), ${ }^{44}$ which in turn is transcriptionally upregulated by JNK via the activator protein 1 (AP1) transcription factor. ${ }^{45,46}$ Preliminary results we obtained from ChIP analysis using U251MG cells concomitantly treated with Notch1sh-AdV and the JNK-inhibitor
SP600125 point towards this indirect regulation as no difference in Sp1-binding to the DR5 promoter was observed (data not shown). This would explain why JNK-inhibition is not sufficient to completely abrogate DR5 induction upon Notch1 downregulation. In this scenario, Notch1 knockdown causes relocation of Sp1 to the DR5 promoter and the concurrent activation of JNK provides a Sp1-binding cofactor increasing its activity. However, further analyses are necessary to conclude on this hypothesis.

Still, the importance of JNK for Sp1-mediated DR5 transcription is quite controversial. Lin et al. ${ }^{37}$ showed that modulation of extracellular-signal-regulated kinase 1/2 (ERK1/2) 

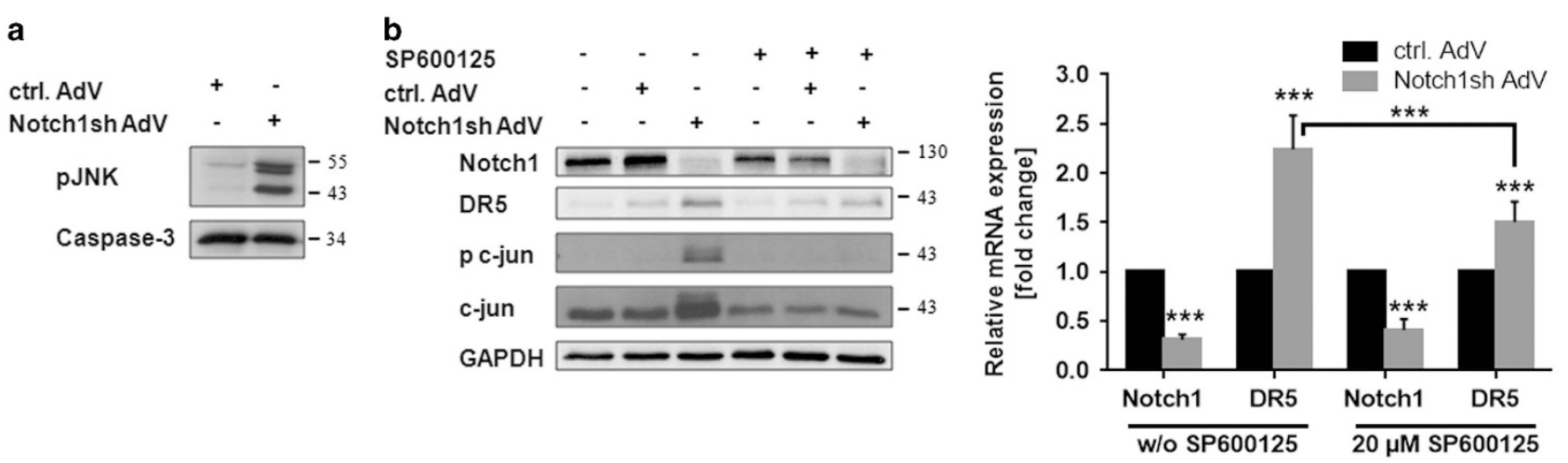

Figure 5 JNK is involved in Notch1-mediated DR5 regulation. (a) JNK is activated following Notch1 knockdown. Immunoblot analysis of Notch1 and phospho-JNK in cytoplasmic lysates of control-AdV and Notch1sh-AdV transduced U251MG cells $72 \mathrm{~h}$ post transduction. (b) U251MG cells transduced with control-AdV or Notch1sh-AdV (48 h) were treated with SP600125 (20 $\mu \mathrm{M})$ for $24 \mathrm{~h}$. Immunoblot analysis for Notch1, DR5, phospho c-jun and c-jun (left panel). Quantitative real-time PCR analysis of Notch1 and DR5 mRNA expression (right panel). Expression data were normalized to internal $18 \mathrm{~S} \mathrm{rRNA}$ expression $(n=3$, mean \pm S.D.). $P$-values were determined by $t$-test (control-AdV versus Notch1sh-AdV) or two-way ANOVA (Notch1sh-AdV w/o SP600125 versus Notch1sh-AdV $20 \mu \mathrm{M}$ SP600125)

but not JNK influenced Sp1-mediated DR5 transcription. In contrast, Higuchi et al. ${ }^{19}$ demonstrated that inhibition of JNK abrogated the binding of $\mathrm{Sp} 1$ to the DR5 promoter while modulating the ERK $1 / 2$ pathway had only moderate effects within this context. Since both studies were performed in ovarian carcinoma and hepatocellular carcinoma, respectively, a cell type and/or tumor entity specific JNK-dependent regulation of Sp1 is highly probable. Besides regulating DR5 expression in a Sp1-dependent manner, JNK might further be responsible for the transcriptional upregulation of the death receptor by activating the transcription factor Stat $1^{47,48}$ which has also been linked to the regulation of DR5 expression. ${ }^{49}$

The pathway of Notch1-mediated DR5 regulation described here is of particular importance for glioblastoma cell survival. TRAIL acts as an effector molecule of immune surveillance by various T-cell subpopulations, NK-cells and macrophages and is therefore important for the elimination of cancer cells by the immune system. ${ }^{50}$ Glioblastoma cells are furthermore also targeted by TRAIL expressed by reactive astrocytes. ${ }^{51,52}$ Since high levels of Notch1 expression are a characteristic feature of glioblastomas, ${ }^{13}$ DR5 protein levels are constantly suppressed. With DR5 being the main signal transducing TRAIL receptor on glioblastoma cells ${ }^{14,16}$ Notch1 signaling allows escape from immune system-induced apoptosis. This is in contrast to the majority of anti-apoptotic signaling pathways deregulated in glioblastomas including the intrinsic anti-apoptotic action of the Notch1 pathway itself, ${ }^{13}$ which protect cancer cells from apoptosis induced through inherent stresses such as oncogenic stress or hypoxia which are pushing them closer to the edge of dying. ${ }^{53}$

With regard to a clinical application, inhibition of Notch1 signaling combined with recombinant TRAIL or DR5 agonists represents an intriguing treatment strategy. Recombinant TRAIL (dulanermin) and several monoclonal antibodies targeting DR5 are in clinical trials both as single agent and in combination therapies. ${ }^{11}$ However, the effects of a combined inhibition of Notch1 signaling and application of DR5 agonists have so far not been evaluated. Amongst different combination therapies analyzed to date, only conatumumab (an agonistic DR5-antibody) together with the cytostatic agent gemcitabine resulted in a longer progression free survival and overall survival in metastatic pancreatic cancer. ${ }^{54}$ Preclinical analysis revealed a synergistic efficacy of TRAIL and chemotherapy in glioblastoma cell lines and primary glioblastoma cells. ${ }^{55,56}$ This synergistic effect was based on death receptor upregulation ${ }^{55,56}$ as well as downregulation of antiapoptotic FLIP protein. ${ }^{56}$ Interestingly, besides negatively regulating DR5 expression, Notch1 positively regulates Mcl$1,{ }^{13,57}$ another important player for TRAIL resistance in glioblastomas, ${ }^{13,58}$ qualifying Notch1 as an even more promising therapeutic target for glioblastomas.

Currently, the $\gamma$-secretase inhibitors (GSIs) RO492097 and MK0752 are used in clinical trials for glioblastoma patients (www.clinicaltrials.gov). Within this context, administration of MK0752 as a single agent resulted in a stable disease in glioblastoma patients. ${ }^{59}$ Since GSIs have several side effects including gastrointestinal toxicities and skin disorders, and target other pathways in addition to Notch signaling, ${ }^{60}$ specific Notch1 inhibitors are of particular interest. For instance, antagonistic antibodies against DLL4 (OMP-21M18, REGN421) and against Notch1 (OMP-52M51) are currently evaluated in phase I and II clinical trials with the latter apparently being well tolerated. ${ }^{60}$ Additionally, further agents targeting Notch1 signaling are in preclinical development, amongst those the 'stapled' peptide SAHM1 that aims at interrupting the binding of NICD to MAML thereby inhibiting the Notch transcription factor complex. ${ }^{60,61}$

Besides having a pivotal role for the success of an experimental therapeutic application of TRAIL or DR5 agonists, inhibition of Notch1 signaling might also be interesting with regard to an efficient TRAIL-mediated immunologic tumor defense. Similarly, anti-tumor vaccines, currently evaluated in clinical trials, ${ }^{62}$ would substantially benefit from an enhanced DR5 expression by the tumor. Of note, Notch1 signaling has furthermore been shown to have an essential role in apoptosis resistance in glioma initiating cells. ${ }^{13,57,63}$ Here, we report that inhibition of the Notch1 pathway also increased susceptibility of glioma initiating cells to TRAIL-mediated apoptosis besides sensitizing conventional glioblastoma cell lines. Considering the 
exceptional high apoptosis resistance of these cells, ${ }^{64,65}$ this finding is of particular interest and further emphasizes the eligibility of Notch1 as a therapeutic target for glioblastoma patients.

\section{Materials and Methods}

Materials. Soluble human TRAIL was obtained from Enzo Life Sciences (Loerrach, Germany). Staurosporine (STS) and the JNK inhibitor SP600125 were purchased from Sigma (Deisenhofen, Germany). GW280264X was kindly provided by GlaxoSmithKline (Stevenage, UK). The antibodies used in this study were obtained as follows: anti-Caspase-3 (Imgenex, San Diego, CA, USA); anti-Caspase-8, anti-PARP (BD Pharmingen, Franklin Lakes, NJ, USA); anti-GAPDH, anti-DR4, anti-Notch1, anti-Sp1 (Santa Cruz Biotechnology, San Diego, CA, USA); antiIntegrin $\beta 4$ (ITGB4), anti-pJNK, anti-cJun, anti-phospho-cJun (Cell Signaling, Danvers, MA, USA); and anti-DR5 (Sigma).

Cell culture. Human glioblastoma long-term cell line U251MG was purchased from the American Type Culture Collection (ATCC, Manassas, VA, USA). NCH468 (primary glioblastoma cells) was kindly provided by Christel Herold-Mende (Department of Neurosurgery, University of Heidelberg, Germany). S24 (glioblastoma initiating cells) ${ }^{66}$ were a kind gift from Wolfgang Wick (DKFZ, Heidelberg, Germany). For the experiments described here, the cells were cultured for no more than eight passages. U251MG and NCH468 cell lines were cultured as described previously. ${ }^{13}$ Glioblastoma-initiating cells (S24) were maintained in HAM'S/F12 (Biochrom, Berlin, Germany) supplemented with 20\% BIT (PELO Biotech, Planegg, Germany) $1 \%$ penicillin/streptomycin, $1 \%$ glutamine (Biochrom), $20 \mathrm{ng} / \mathrm{ml} \mathrm{EGF}$ (Reliatech, Wolfenbuettel, Germany) and $20 \mathrm{ng} / \mathrm{ml}$ bFGF (Reliatech) and cultured at $37^{\circ} \mathrm{C}$ in a $5 \% \mathrm{CO}_{2}$ atmosphere.

Cell lines were regularly tested for the presence of contamination using multiplex cell contamination test provided by the German Cancer Research Center (DKFZ) core facility. ${ }^{67}$

Transfection. Glioblastoma cells were transiently transfected with siRNA oligonucleotides using Lipofectamine 2000 (Life Technologies, Carlsbad, CA, USA). Sp1 siRNA \#1 and \#2 were obtained from Thermo Scientific (Waltham, MA, USA, \#D-026959-01, \#D-026959-02) and used in a concentration of $50 \mathrm{nM}$. DR5 siRNA was purchased from Life Technologies (\#s16756) and used in a concentration of $10 \mathrm{nM}$. A non-specific siRNA served as a control (Thermo Scientific, \#D-001810-01).

Adenoviral transduction. The recombinant adenoviruses Ad-sh-Notch1 (referred to as Notch1sh AdV) and Ad-sh-scrmbl (referred to as ctrl. AdV) were obtained from SIRION BIOTECH (Martinsried, Germany). The recombinant adenoviruses Ad-mNICD1 (referred to as NICD1 AdV) and Ad-control overexpression (referred to as control OE-AdV) were kind gifts from Mirko HH Schmidt (Institute of Neurology, University of Frankfurt, Germany) and Stefan Herzig (DKFZ) respectively. Directly after seeding, glioblastoma cells were transduced with recombinant adenoviruses using a multiplicity of infection (MOI) of 25-100 (U251MG), 100-300 (NCH468 and S24) or 50-100 (astrocytes).

Reporter gene assay. DR5 reporter gene constructs (pDR5/-198, pDR5mSp1-1, pDR5mSp1-2) ${ }^{21}$ were kindly provided by Toshiyuki Sakai (Department of Preventive Medicine, Kyoto Prefectural University of Medicine, Kyoto, Japan). Forty-eight hours after adenoviral transduction, cells were cotransfected with Renilla luciferase pRL-SV40 (Promega, Madison, WI, USA) and pDR5/-198, pDR5mSp1-1 or pDR5mSp1-2, respectively. Twenty-four hours post transfection, cell lysates were prepared. Activities of both firefly and Renilla luciferase were determined using the dual luciferase reporter assay system (Promega) according to the manufacturer's instructions.

Quantitative PCR analysis. Quantitative real-time PCR was performed as described previously. ${ }^{13}$ Following primer pairs were used: $18 \mathrm{~S}$ : $5^{\prime}$-CATGG CCGTTCTTAGTTGGT-3' (forward) 5'-ATGCCAGAGTCTCGTTCGTT-3' (reverse) Notch1: 5'-GGGCCCTGAATTTCACTGT-3' (forward) 5'-CGCAGAGGGTTGTATT GGTT-3' (reverse) DR5: 5'-CAGGTGGACACAATCCCTCT-3' (forward) 5'-AAGA CCCTTGTGCTCGTTGT-3' (reverse) Hey1: 5'-CGAAATCCCAAACTCCGATA-3' (forward) 5'-TGGATCACCTGAAATGCTG-3' (reverse).
Flow cytometry. For measurement of cell death, glioblastoma cells were treated as indicated, detached, and stained with Annexin V-FITC (Apoptosis Detection Kit I, BD Pharmingen) according to the manufacturer's instructions.

For measurement of cell surface expression of DR4 and DR5 glioblastoma cells were incubated with cell dissociation buffer (Life Technologies) for $30 \mathrm{~min}$ at $37^{\circ} \mathrm{C}$ and harvested. Cells were stained with a FITC-labeled anti-DR4 antibody $(10 \mu \mathrm{g} / \mathrm{ml}$, Axxora, Loerrach, Germany), a FITC-labeled anti-DR5 antibody (10 $\mu \mathrm{g} / \mathrm{ml}$; Axxora) or a FITC-labeled IgG1-isotype control antibody ( $10 \mu \mathrm{g} / \mathrm{ml}$; Ancell, Bayport, MN, USA) for $60 \mathrm{~min}$ at room temperature. Cells were washed, resuspended in PBS containing $0.5 \% \mathrm{FCS}$ and propidium iodide $(1 \mu \mathrm{g} / \mathrm{ml})$.

Cells were subjected to flow cytometry analysis using a Becton Dickinson FACScalibur cytometer and Cell Quest Software (Heidelberg, Germany).

Immunoblot analysis. Whole cellular lysate generation and immunoblot analysis was performed as described previously. ${ }^{13}$ For membrane fractionation, cells were processed with a plasma membrane protein extraction kit (BioVision, Zuerich, Switzerland) following the manufacturer's instructions.

DISC-Immunoprecipitation. Cells were incubated with FLAG-tagged TRAIL (Enzo Life Sciences; $500 \mathrm{ng} / \mathrm{ml}$ ) for the indicated times, washed with PBS and subsequently lysed in lysis buffer $(20 \mathrm{mM}$ Tris- $\mathrm{HCl}, \mathrm{pH} 7.4 ; 150 \mathrm{nM} \mathrm{NaCl} ; 0.2 \%$ Nonidet P40; 10\% Glycerol; protease and phosphatase inhibitor cocktail (Life Technologies)). The TRAIL-DISC was immunoprecipitated from precleared lysates overnight with $20 \mu \mathrm{l}$ anti-FLAG antibody M2-conjugated agarose beads (Sigma). Before immunoblot analysis, beads were recovered by centrifugation and washed four times with lysis buffer.

Chromatin-Immunoprecipitation. A total of $1 \times 10^{7}$ U251MG cells were transduced with recombinant adenoviruses. Seventy-two hours post transduction the cells were cross-linked with $1 \%$ formaldehyde and chromatin fractions were prepared exactly as described previously. ${ }^{68}$ After clearance of non-specifically bound chromatin fragments, supernatants equivalent to $25 \mu \mathrm{g}$ DNA were incubated with $2 \mu \mathrm{g}$ of Sp1 antibody or $2 \mu \mathrm{g}$ of rabbit IgG antibody as control (both provided in the same kit; Millipore, Billerica, MA, USA, \#17-601; Lot: JBC1920619). Next day, the immune-selected chromatin was eluted from the protein $A / G$ agarose beads adding $250 \mu \mathrm{l}$ of elution buffer ( $1 \% \mathrm{SDS}, 100 \mathrm{mM} \mathrm{NaHCO}$ ), diluted $1: 1$ in de-crosslinking buffer $(320 \mathrm{mM} \mathrm{NaCl}, 80 \mathrm{mM}$ Tris pH 8, $20 \mathrm{mM}$ EDTA pH 8 and $100 \mu \mathrm{g} / \mathrm{ml}$ proteinase $\mathrm{K}$ ) and incubated overnight at $65^{\circ} \mathrm{C}$. Real-time PCR analysis of immunoprecipitated chromatin was done using the following DR5 promoterspecific primers: forward 5'-AGGTTAGTTCCGGTCCCTTC-3'; reverse: 5'-CGCGT GCTGATTTATGTGTC- $3^{\prime} .^{19}$ PCR products were quantified relative to the control using rabbit $\lg G$ for unspecific binding.

Colony formation assay. To assess colony formation cells were seeded in 6-well plates (U251MG: $1 \times 10^{4}$ cells; NCH468: $4 \times 10^{4}$ cells) and incubated for five days (U251MG) and six days (NCH468), respectively before crystal violet staining. Colony count was determined using the Clono Counter ${ }^{69}$ software. Synergy was evaluated as described previously. ${ }^{70}$

Statistical methods. Significant differences were identified by two-way ANOVA, one-way ANOVA or $t$-test. The test used in a certain analysis is stated in the respective figure legend. Whenever necessary $P$-values were corrected for multiple testing using the Holm-Sidak test. Throughout, $P$-values $<0.05$ were considered significant and are indicated as follows: ${ }^{\star} P<0.05,{ }^{* *} P<0.01,{ }^{\star \star *} P<0.001$.

\section{Conflict of Interest}

The authors declare no conflict of interest.

Acknowledgements. We thank Stefan Herzig (DKFZ) and Mirko HH Schmidt (Institute of Neurology, University of Frankfurt, Germany) for providing recombinant adenoviruses, Toshiyuki Sakai (Department of Preventive Medicine, Kyoto Prefectural University of Medicine, Kyoto, Japan) for kindly donating DR5 reporter gene constructs, Christel Herold-Mende (Department of Neurosurgery, University of Heidelberg, Heidelberg, Germany) for providing primary glioblastoma cell lines and Wolfgang Wick (DKFZ, Heidelberg, Germany) for providing glioblastoma stem-cell like cells. This work was supported by a grant from the Federal Ministry of Education and Research (BMBF) to WR (NGFNplus Brain Tumor Network; grant number 01GS0883). 
1. Radtke F, Raj K. The role of Notch in tumorigenesis: oncogene or tumour suppressor? Nat Rev Cancer 2003; 3: 756-767.

2. Hori K, Sen A, Artavanis-Tsakonas S. Notch signaling at a glance. J Cell Sci 2013; 126: 2135-2140.

3. Jarriault S, Le Bail O, Hirsinger E, Pourquié O, Logeat F, Strong CF et al. Deltaactivation of notch-1 signaling results in HES-1 transactivation. Mol Cell Biol 1998; 18 : 7423-7431.

4. Bailey AM, Posakony JW. Suppressor of hairless directly activates transcription of enhancer of split complex genes in response to Notch receptor activity. Genes Dev 1995; 9: 2609-2622.

5. Ronchini C, Capobianco AJ. Induction of cyclin D1 transcription and CDK2 activity by Notch (ic): implication for cell cycle disruption in transformation by Notch(ic). Mol Cell Biol 2001; 21: 5925-5934.

6. Weng AP, Millholland JM, Yashiro-Ohtani Y, Arcangeli ML, Lau A, Wai C et al. c-Myc is an important direct target of Notch1 in T-cell acute lymphoblastic leukemia/lymphoma. Genes Dev 2006; 20: 2096-2109.

7. Rangarajan A, Talora C, Okuyama R, Nicolas M, Mammucari C, Oh H et al. Notch signaling is a direct determinant of keratinocyte growth arrest and entry into differentiation. EMBO $\mathrm{J}$ 2001; 20: 3427-3436.

8. Chen $Y$, Li D, Liu H, Xu H, Zheng H, Qian F et al. Notch-1 signaling facilitates survivin expression in human non-small cell lung cancer cells. Cancer Biol Ther 2011; 11: 14-21.

9. Gonzalvez F, Ashkenazi A. New insights into apoptosis signaling by Apo2L/TRAIL. Oncogene 2010; 29: 4752-4765.

10. White-Gilbertson S, Rubinchik S, Voelkel-Johnson C. Transformation, translation and TRAIL: an unexpected intersection. Cytokine Growth Factor Rev 2008; 19: 167-172.

11. den Hollander MW, Gietema JA, de Jong S, Walenkamp AM, Reyners AK, Oldenhuis CN et al. Translating TRAIL-receptor targeting agents to the clinic. Cancer Lett 2013; 332 194-201.

12. Kruyt FA. TRAIL and cancer therapy. Cancer Lett 2008; 263: 14-25.

13. Fassl A, Tagscherer KE, Richter J, Berriel Diaz M, Alcantara Llaguno SR et al. Notch1 signaling promotes survival of glioblastoma cells via EGFR-mediated induction of anti-apoptotic Mcl-1. Oncogene 2012; 31: 4698-4708.

14. Bellail AC, Tse MC, Song JH, Phuphanich S, Olson JJ, Sun SY et al. DR5-mediated DISC controls caspase-8 cleavage and initiation of apoptosis in human glioblastomas. J Cell Mol Med 2010; 14: 1303-1317.

15. Elias A, Siegelin MD, Steinmüller A, von Deimling A, Lass U, Korn B et al. Epigenetic silencing of death receptor 4 mediates tumor necrosis factor-related apoptosis-inducing ligand resistance in gliomas. Clin Cancer Res 2009; 15: 5457-5465.

16. Nagane M, Shimizu S, Mori E, Kataoka S, Shiokawa Y. Predominant antitumor effects by fully human anti-TRAIL-receptor 2 (DR5) monoclonal antibodies in human glioma cells in vitro and in vivo. Neuro Oncol 2010; 12: 687-700.

17. Tian X, Ye J, Alonso-Basanta M, Hahn SM, Koumenis C, Dorsey JF. Modulation of CCAAT/enhancer binding protein homologous protein (CHOP)-dependent DR5 expression by nelfinavir sensitizes glioblastoma multiforme cells to tumor necrosis factor-related apoptosis-inducing ligand (TRAIL). J Biol Chem 2011; 286: 29408-29416.

18. Kim EH, Yoon MJ, Kim SU, Kwon TK, Sohn S, Choi KS. Arsenic trioxide sensitizes human glioma cells, but not normal astrocytes, to TRAIL-induced apoptosis via CCAAT/enhancerbinding protein homologous protein-dependent DR5 up-regulation. Cancer Res 2008; 68: 266-275.

19. Higuchi H, Grambihler A, Canbay A, Bronk SF, Gores GJ. Bile acids up-regulate death receptor 5/TRAIL-receptor 2 expression via a c-Jun N-terminal kinase-dependent pathway involving Sp1. J Biol Chem 2004; 279: 51-60.

20. Sun M, Zhang J, Liu S, Liu Y, Zheng D. Sp1 is involved in 8-chloro-adenosine-upregulated death receptor 5 expression in human hepatoma cells. Oncol Rep 2008; 19: 177-185.

21. Yoshida T, Maeda A, Tani N, Sakai T. Promoter structure and transcription initiation sites of the human death receptor 5/TRAIL-R2 gene. FEBS Lett 2001; 507: 381-385.

22. Roth W, Isenmann S, Naumann U, Kügler S, Bähr M, Dichgans J et al. Locoregional Apo2L/TRAIL eradicates intracranial human malignant glioma xenografts in athymic mice in the absence of neurotoxicity. Biochem Biophys Res Commun 1999; 265: 479-483.

23. Liu Y, Lang F, Xie X, Prabhu S, Xu J, Sampath D et al. Efficacy of adenovirally expressed soluble TRAIL in human glioma organotypic slice culture and glioma xenografts. Cell Death Dis 2011; 2: e121.

24. Perlstein B, Finniss SA, Miller C, Okhrimenko H, Kazimirsky G, Cazacu S et al. TRAIL conjugated to nanoparticles exhibits increased anti-tumor activities in glioma cells and glioma stem cells in vitro and in vivo. Neuro Oncol 2013; 15: 29-40.

25. Herbst RS, Kurzrock R, Hong DS, Valdivieso M, Hsu CP, Goyal L et al. A first-in-human study of conatumumab in adult patients with advanced solid tumors. Clin Cancer Res 2010; 16: 5883-5891.

26. Knight MJ, Riffkin CD, Muscat AM, Ashley DM, Hawkins CJ. Analysis of FasL and TRAIL induced apoptosis pathways in glioma cells. Oncogene 2001; 20: 5789-5798.

27. Panner A, James CD, Berger MS, Pieper RO. mTOR controls FLIPS translation and TRAIL sensitivity in glioblastoma multiforme cells. Mol Cell Biol 2005; 25: 8809-8823.

28. Lavrik I, Golks A, Krammer PH. Death receptor signaling. J Cell Sci 2005; 118 265-267.

29. Sartorius U, Schmitz I, Krammer PH. Molecular mechanisms of death-receptor-mediated apoptosis. Chembiochem 2001; 2: 20-29.
30. Portanova P, Notaro A, Pellerito O, Sabella S, Giuliano M, Calvaruso G. Notch inhibition restores TRAlL-mediated apoptosis via AP1-dependent upregulation of DR4 and DR5 TRAIL receptors in MDA-MB-231 breast cancer cells. Int J Oncol 2013; 43: 121-130.

31. Wang C, Qi R, Li N, Wang Z, An H, Zhang Q et al. Notch1 signaling sensitizes tumor necrosis factor-related apoptosis-inducing ligand-induced apoptosis in human hepatocellular carcinoma cells by inhibiting Akt/Hdm2-mediated p53 degradation and up-regulating p53dependent DR5 expression. J Biol Chem 2009; 284: 16183-16190.

32. Burton TR, Henson ES, Azad MB, Brown M, Eisenstat DD, Gibson SB. BNIP3 acts as transcriptional repressor of death receptor-5 expression and prevents TRAlL-induced cell death in gliomas. Cell Death Dis 2013; 4: e587.

33. Henson ES, Johnston JB, Gibson SB. The role of TRAIL death receptors in the treatment of hematological malignancies. Leuk Lymphoma 2008; 49: 27-35.

34. Kim MO, Moon DO, Kang CH, Kwon TK, Choi YH, Kim GY beta-lonone enhances TRAlL-induced apoptosis in hepatocellular carcinoma cells through Sp1-dependent upregulation of DR5 and downregulation of NF-kappaB activity. Mol Cancer Ther 2010; 9: 833-843.

35. Lin T, Ding Z, Li N, Xu J, Luo G, Liu J et al. 2-Tellurium-bridged beta-cyclodextrin, a thioredoxin reductase inhibitor, sensitizes human breast cancer cells to TRAIL-induced apoptosis through DR5 induction and NF-kappaB suppression. Carcinogenesis 2011; 32 : 154-167.

36. Kim YH, Park JW, Lee JY, Kwon TK. Sodium butyrate sensitizes TRAIL-mediated apoptosis by induction of transcription from the DR5 gene promoter through Sp1 sites in colon cancer cells. Carcinogenesis 2004; 25: 1813-1820.

37. Lin T, Chen Y, Ding Z, Luo G, Liu J, Shen J. Novel insights into the synergistic interaction of a thioredoxin reductase inhibitor and TRAIL: the activation of the ASK1-ERK-Sp1 pathway. PLoS One 2013; 8: e63966.

38. Kim JW, Kim MJ, Kim KJ, Yun HJ, Chae JS, Hwang SG et al. Notch interferes with the scaffold function of JNK-interacting protein 1 to inhibit the JNK signaling pathway. Proc Natl Acad Sci USA 2005; 102: 14308-14313.

39. Huang PH, Wang D, Chuang HC, Wei S, Kulp SK, Chen CS. alpha-Tocopheryl succinate and derivatives mediate the transcriptional repression of androgen receptor in prostate cancer cells by targeting the PP2A-JNK-Sp1-signaling axis. Carcinogenesis 2009; 30: $1125-1131$.

40. Chuang JY, Wang YT, Yeh SH, Liu YW, Chang WC, Hung JJ. Phosphorylation by c-Jun $\mathrm{NH} 2$-terminal kinase 1 regulates the stability of transcription factor Sp1 during mitosis. Mol Biol Cell 2008; 19: 1139-1151.

41. Wang YT, Chuang JY, Shen MR, Yang WB, Chang WC, Hung JJ. Sumoylation of specificity protein 1 augments its degradation by changing the localization and increasing the specificity protein 1 proteolytic process. J Mol Biol 2008; 380: 869-885

42. Blaine SA, Wick M, Dessev C, Nemenoff RA. Induction of CPLA2 in lung epithelial cells and non-small cell lung cancer is mediated by Sp1 and c-Jun. J Biol Chem 2001; 276: 42737-42743.

43. Kardassis D, Papakosta P, Pardali K, Moustakas A. C-Jun transactivates the promoter of the human $\mathrm{p} 21$ (WAF1/Cip1) gene by acting as a superactivator of the ubiquitous transcription factor Sp1. J Biol Chem 1999; 274: 29572-29581.

44. Tai TC, Wong-Faull DC, Claycomb R, Wong DL. Hypoxia and adrenergic function: molecular mechanisms related to Egr-1 and Sp1 activation. Brain Res 2010; 1353: 14-27.

45. Inostroza J, Saenz L, Calaf G, Cabello G, Parra E. Role of the phosphatase PP4 in the activation of JNK-1 in prostate carcinoma cell lines PC-3 and LNCaP resulting in increased AP-1 and EGR-1 activity. Biol Res 2005; 38: 163-178.

46. Hoffmann E, Ashouri J, Wolter S, Doerrie A, Dittrich-Breiholz O, Schneider $\mathrm{H}$ et al. Transcriptional regulation of EGR-1 by the interleukin-1-JNK-MKK7-c-Jun pathway. J Biol Chem 2008; 283: 12120-12128.

47. Lo RK, Wise H, Wong YH. Prostacyclin receptor induces STAT1 and STAT3 phosphorylations in human erythroleukemia cells: a mechanism requiring PTX-insensitive G proteins, ERK and JNK. Cell Signal 2006; 18: 307-317.

48. Zhao KW, Li D, Zhao Q, Huang Y, Silverman RH, Sims PJ et al. Interferon-alpha-induced expression of phospholipid scramblase 1 through STAT 1 requires the sequential activation of protein kinase Cdelta and JNK. J Biol Chem 2005; 280: 42707-42714.

49. Meng RD, El-Deiry WS. p53-independent upregulation of KILLER/DR5 TRAIL receptor expression by glucocorticoids and interferon-gamma. Exp Cell Res 2001; 262: 154-169.

50. Smyth MJ, Takeda K, Hayakawa Y, Peschon JJ, van den Brink MR, Yagita H. Nature's TRAIL -on a path to cancer immunotherapy. Immunity 2003; 18: 1-6.

51. Nakamura M, Rieger J, Weller M, Kim J, Kleihues P, Ohgaki H. APO2L/TRAlL expression in human brain tumors. Acta Neuropathol 2000; 99: 1-6.

52. Rieger J, Ohgaki H, Kleihues P, Weller M. Human astrocytic brain tumors express AP02L TRAIL. Acta Neuropathol 1999; 97: 1-4

53. Lopez J, Tait SW. Mitochondrial apoptosis: killing cancer using the enemy within. Br J Cancer 2015; 112: 957-962

54. Kindler HL, Richards DA, Garbo LE, Garon EB, Stephenson JJ Jr, Rocha-Lima CM et al. A randomized, placebo-controlled phase 2 study of ganitumab (AMG 479) or conatumumab (AMG 655) in combination with gemcitabine in patients with metastatic pancreatic cancer. Ann Oncol 2012; 23: 2834-2842.

55. Nagane M, Pan G, Weddle JJ, Dixit VM, Cavenee WK, Huang HJ. Increased death receptor 5 expression by chemotherapeutic agents in human gliomas causes synergistic 
cytotoxicity with tumor necrosis factor-related apoptosis-inducing ligand in vitro and in vivo. Cancer Res 2000; 60: 847-853.

56. Koschny R, Holland H, Sykora J, Haas TL, Sprick MR, Ganten TM et al. Bortezomib sensitizes primary human astrocytoma cells of WHO grades I to IV for tumor necrosis factorrelated apoptosis-inducing ligand-induced apoptosis. Clin Cancer Res 2007; 13: 3403-3412.

57. Wang J, Wakeman TP, Lathia JD, Hjelmeland AB, Wang XF, White RR et al. Notch promotes radioresistance of glioma stem cells. Stem Cells 2010; 28: 17-28.

58. Murphy AC, Weyhenmeyer B, Noonan J, Kilbride SM, Schimansky S, Loh KP et al. Modulation of Mcl-1 sensitizes glioblastoma to TRAIL-induced apoptosis. Apoptosis 2014; 19: 629-642.

59. Krop I, Demuth T, Guthrie T, Wen PY, Mason WP, Chinnaiyan P et al. Phase I pharmacologic and pharmacodynamic study of the gamma secretase (Notch) inhibitor MK-0752 in adult patients with advanced solid tumors. J Clin Oncol 2012; 30: 2307-2313.

60. Takebe N, Nguyen D, Yang SX. Targeting notch signaling pathway in cancer: clinical development advances and challenges. Pharmacol Ther 2014; 141: 140-149.

61. Moellering RE, Cornejo M, Davis TN, Del Bianco C, Aster JC, Blacklow SC et al. Direct inhibition of the NOTCH transcription factor complex. Nature 2009; 462: 182-188.

62. Vauleon E, Avril T, Collet B, Mosser J, Quillien V. Overview of cellular immunotherapy for patients with glioblastoma. Clin Dev Immunol 2010; 2010: 689171

63. Fan X, Khaki L, Zhu TS, Soules ME, Talsma CE, Gul N et al. NOTCH pathway blockade depletes CD133-positive glioblastoma cells and inhibits growth of tumor neurospheres and xenografts. Stem Cells 2010; 28: 5-16.

64. Bao S, Wu Q, McLendon RE, Hao Y, Shi Q, Hjelmeland AB et al. Glioma stem cells promote radioresistance by preferential activation of the DNA damage response. Nature 2006; 444 : 756-760.

65. Beier D, Schulz JB, Beier CP. Chemoresistance of glioblastoma cancer stem cells-much more complex than expected. Mol Cancer 2011; 10: 128.
66. Lemke D, Pfenning PN, Sahm F, Klein AC, Kempf T, Warnken U et al. Costimulatory protein $4 \mathrm{lgB} 7 \mathrm{H} 3$ drives the malignant phenotype of glioblastoma by mediating immune escape and invasiveness. Clin Cancer Res 2012; 18: 105-117.

67. Schmitt M, Pawlita M. High-throughput detection and multiplex identification of cell contaminations. Nucleic Acids Res 2009; 37: e119.

68. De-Castro Arce J, Gockel-Krzikalla E, Rosl F. Retinoic acid receptor beta silences human papillomavirus-18 oncogene expression by induction of de novo methylation and heterochromatinization of the viral control region. J Biol Chem 2007; 282: 28520-28529.

69. Niyazi M, Niyazi I, Belka C. Counting colonies of clonogenic assays by using densitometric software. Radiat Oncol 2007; 2: 4.

70. Tagscherer KE, Fassl A, Campos B, Farhadi M, Kraemer A, Böck BC et al. Apoptosis-based treatment of glioblastomas with $A B T-737$, a novel small molecule inhibitor of Bcl-2 family proteins. Oncogene 2008; 27: 6646-6656.

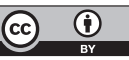

Cell Death and Disease is an open-access journal published by Nature Publishing Group. This work is licensed under a Creative Commons Attribution 4.0 International License. The images or other third party material in this article are included in the article's Creative Commons license, unless indicated otherwise in the credit line; if the material is not included under the Creative Commons license, users will need to obtain permission from the license holder to reproduce the material. To view a copy of this license, visit http://creativecommons.org/licenses/by/4.0/

Supplementary Information accompanies this paper on Cell Death and Disease website (http://www.nature.com/cddis) 